Удк 378.015.31:159.942

\title{
ЭМОЦИОНАЛЬНОЕ БЛАГОПОЛУЧИЕ КАК ПОКАЗАТЕЛЬ СОЦИАЛЬНО-ПСИХОЛОГИЧЕСКОЙ БЕЗОПАСНОСТИ СТУДЕНТОВ
}

\author{
Родионова Елена Викторовна1, \\ eva@tpu.ru \\ Конюхова Татьяна Васильевна ${ }^{1}$, \\ konykhova@tpu.ru \\ Конюхова Екатерина Тимофеевна², \\ konjuhova50@mail.ru
}

\begin{abstract}
${ }^{1}$ Национальный исследовательский Томский политехнический университет, Россия, 634050, г. Томск, пр. Ленина, 30

${ }^{2}$ Новокузнецкий институт (филиал) Кемеровский государственный университет, Россия, 654027, г. Новокузнецк, ул. Циолковского, 23
\end{abstract}

Родионова Елена Викторовна, кандидат философских наук, доцент отделения социальногуманитарных наук Школы базовой инженерной подготовки Национального исследовательского Томского политехнического университета.

Конюхова Татьяна Васильевна, кандидат философских наук, доцент отделения социальногуманитарных наук Школы базовой инженерной подготовки Национального исследовательского Томского политехнического университета.

Конюхова Екатерина Тимофеевна, кандидат педагогических наук, доцент кафедры психологии и общей педагогики Новокузнецкого института (филиала) Кемеровского государственного университета.

Рассматривается проблематика социально-психологической безопасности студентов, составляющей которой является эмоциональное благополучие. Психологическая безопасность проявляется в ошущении субъектом своей защищенности, референтной значимости среды для него и удовлетворенности процессами взаимодействия. Немаловажную роль здесь играет состояние эмоционального фона, эмоциональной осознанности субъекта, умение их выражать и осуществлять их регуляцию. Одним из условий обретения эмоционального благополучия выступает развитый эмоциональный интеллект. Сегодня он рассматривается как необходимый элемент, позволяющий владеть собой в различных ситуациях, эффективно налаживать и выстраивать отношения с другими субъектами деятельности, социализироваться в жизни. Это дает возможность обрести состояние уверенности, спокойствия и удовлетворения. Цель: оценить эффективность занятий по развитию эмоционального интеллекта студентов младших курсов, влияющих на формирование и/или поддержание эмоционального благополучия и социально-психологической безопасности. Методы: общетеоретические методы научного анализа, синтеза, моделирования; практические методы (качественное глубинное интервью; диагностический метод (опросник ЭмИн Д.В. Люсина, тест на определение уровня эмоционального интеллекта Н. Холла); экспериментальный метод для проведения констатирующих, формирующих и контрольных этапов исследования; методы математической статистики). Результаты: формирующая деятельность позволяет развивать эмоциональный интеллект, влияющий на поддержание достаточного уровня общего эмоционального благополучия студентов-первокурсников и ощущения социально-психологической безопасности личности.

Ключевые слова: Социально-психологическая безопасность, эмоциональное благополучие студентов, эмоциональный интеллект, цифровое поколение, эмоциональная осведомленность, эмпатия, психическое здоровье студентов. 


\section{Введение}

Внедрение цифровых технологий в образовательную среду меняет способы восприятия информации, стили мышления в освоении профессиональных знаний и навыков современных студентов. Активная информатизация общества порождает различные угрозы. Внешние угрозы (большой объем информации, проблемы ее достоверности) затрудняют познание окружающего мира. Внутренние угрозы - неспособность критически оценивать информацию, замена реального общения виртуальным, как следствие сложность в оценке людей и гибкости поведения. Все это вызывает напряжение, скованность, снижает креативность, эффективность функционирования в нестандартных ситуациях. Суммарно это отражается в отсутствии психологического и эмоционального благополучия, которое необходимо для поддержания и развития потенциала личности и которые являются основополагающими компонентами человеческого капитала. Такое положение лишь подчеркивает актуальность вопросов психологической безопасности современного человека.

Наиболее значимой социальной средой, в которой происходит формирование и раскрытие личностного потенциала, является образовательная система и, более того, среда профессионального становления. Чтобы максимально выполнять свои функции, образовательная среда должна быть безопасной для её участников. Различные аспекты психологической безопасности такой среды сегодня представляют все больший интерес для исследователей ее предметного поля, структуры, видов и т. д. В русле заявленной тематики можно отметить труды отечественных ученых И.А. Баевой, Г.В. Грачева, И.В. Бурмистровой, Е.Б. Лактионовой, Э.Э. Сыманюк и др. [1-5]. Среди зарубежных исследователей для нас представляют интерес работы S. Hong, M.K. Eamon, C. Hilarski, M. Baer. В них подчеркивается важная роль безопасности образовательной среды в поддержании психологического здоровья ее участников [6-8].

Определяя предметное поле нашего исследования, отмечаем, что в соответствии с концепцией И.А. Баевой психологически безопасной можно назвать ту образовательную среду, состояние которой будет соответствовать следующим условиям:

- ощущение защищенности от психологического насилия для всех участников при взаимодействии в образовательной среде;

- ценностная значимость среды для её участников;

- удовлетворенность участников в процессе осуществления коммуникации [9].

Таким образом, можно констатировать, что психологическая безопасность - это состояние динамического равновесия между отношением к себе, миру, другим; ощущение удовлетворенности субъекта от взаимодействия с другими, ощущение отсутствия угроз от внешнего и внутреннего мира. Все это «позволяет сохранить целостность субъекта, реализовать его духовно-психический потенциал в процессе жизнедеятельности» [10].

В своей работе О.Ю. Зотова отмечает, что социально-психологическая безопасность личности, как психологическое образование, имеет сложную структуру и является развивающейся системой таких аспектов методологических подходов, как субъектный, деятельностный, системный [11]. Считаем, что социально-психологическая безопасность личности складывается в социальных отношениях. В ходе коммуникации формируется социально-психологическая общность, которая является предпосылкой эффективного взаимодействия. И напротив, при состоянии опасности включается защитная функция и это способствует отделению субъекта и его пространства. Такая ситуация порождает эмоциональное напряжение и сопротивление субъекта внешним (нарушение общепринятых норм) и внутренним угрозам (уход от контактов) и приводит к 
поиску деструктивных способов выхода из негативной ситуации [12]. Последствиями может быть специфическое изменение личности, влияющее на его психологическое благополучие.

\section{Методы исследования}

Актуальность описанного проблемного поля позволяет нам сформулировать объект и предмет исследования.

Объект исследования: социально-психологическая безопасность студентов.

Предмет исследования: эмоциональное благополучие студентов как компонент социально-психологической безопасности.

Цель исследования - оценить эффективность занятий по развитию эмоционального интеллекта (EQ) студентов младших курсов, влияющих на формирование и/или поддержание эмоционального благополучия и социально-психологической безопасности.

Гипотеза исследования: полагаем, что проведение цикла внеаудиторных занятий для студентов 1-го года обучения будет способствовать повышению их уровня эмоционального благополучия через развитие эмоционального интеллекта.

В качестве методологической основы выступили общетеоретические методы: научный анализ, синтез, моделирование. В качестве практических методов применялись: качественное глубинное интервью; диагностический метод (опросник ЭмИн Д.В. Люсина, тест на определение уровня эмоционального интеллекта Н. Холла); экспериментальный метод для проведения констатирующих, формирующих и контрольных этапов исследования; методы математической статистики.

Этапы исследования:

- теоретико-методологический анализ информационных источников по предметному полю исследования, определение базовых понятий;

- глубинные интервью со студентами 1-го курса с целью определения контента категории «эмоциональное благополучие» с точки зрения респондентов и выявления факторов, влияющих на эмоциональное благополучие;

- методическая разработка серии встреч для повышения уровня эмоционального благополучия студентов через развитие их эмоционального интеллекта;

- констатирующее диагностирование: определение уровня эмоционального интеллекта у студентов 1-го курса в начале первого семестра обучения;

- проведение серии внеаудиторных встреч с контрольной группой;

- контролирующее диагностирование уровня EQ после прохождения цикла встреч в экспериментальной группе и замер уровня EQ в контрольной группе.

\section{Результаты и дискуссионные вопросы}

Базовый теоретический конструкт социально-психологическая безопасность личности - это психологическое образование со сложной структурой. В данном исследовании мы будет понимать под ним состояние субъекта, приносящее удовлетворение коммуникациями (дружественное, гармоничное, толерантное общение), чувство защищенности (отсутствие проблем в коммуникации, конфликтов, наличие толерантности), строящееся на динамическом балансе между внутренним потенциалом личности и внешней средой [11]. Также важно отметить, что социально-психологическая безопасность выступает как целостный показатель отношения личности к окружающей среде в определенный момент, с определенными ожиданиями, притязаниями субъекта относительно уровня соответствия его возможностей и его потенциала [10]. 
Среда, которая обладает высокой степенью безопасности, характеризуется расширением социального пространства для познания, обмена, взаимодействия субъектов. Иными словами, она создает условия для эмоционального благополучия ее участников. Нам представляется, что именно через понятие «эмоциональное благополучие» можно более глубоко понять те изменения, которые происходят в эмоциональной жизни цифрового поколения. Отметим также, что Всемирная организация здравоохранения (ВО3) в последнее время активно использует термин «благополучие», чтобы отойти от дихотомии «здоровье-болезнь».

Как уже было отмечено, изменение за счет цифровизации способов коммуникации современного поколения вызывает своего рода «отгораживание от мира» [13]. С одной стороны, эмоциональные затруднения цифрового поколения активно изучаются, с другой - нет систематизированного характера, четко обозначенных критериев благополучия или неблагополучия в этих исследованиях. Психолог Эрик Эриксон, автор теории психосоциального развития личности, отмечал, что для обеспечения эмоционального благополучия необходимы умения выстраивать коммуникацию, создавать близкие отношения, проявлять индивидуальность, проявлять активность [14].

Теоретический анализ соответствующей литературы показывает различные подходы к определению эмоционального благополучия, например рассмотрение эмоционального благополучия как успешности выражения и регуляции эмоций $[15,16]$; как показателя и отражения психологического благополучия личности в целом [17]; как синонима эмоционального здоровья [18] и т. д.

Поскольку на сегодня нет целостной концептуальной позиции относительно эмоционального благополучия, обозначим, что в нашем исследовании под эмоциональным благополучием студентов понимается эмоционально-положительное самочувствие, отражающее успешность эмоциональной регуляции социальных отношений в образовательном пространстве, своего рода положительное эмоциональное отношение к себе и миру, способность преобразовывать отрицательные эмоции и порождать положительные ощущения в период обучения в университете.

Содержательные характеристики эмоционального благополучия, обозначенные в исследованиях [15, 19], включают:

- состояние уверенности, спокойствия и удовлетворения;

- преобладающие позитивные отношения с другими (общий позитивный настрой);

- субъективное ощущение счастья;

- осознание своих эмоций и возможность регулировать свои реакции на эмоции.

В сентябре 2018 г. нами было проведено восемь глубинных интервью со студентами 1-го курса, только что поступившими в вузы Сибирского федерального округа (НИ ТПУ, КемГУ, НФИ КемГУ). Основная цель интервью - выявить, что студенты понимают под «эмоциональным благополучием» в целом и какие факторы, на их взгляд, влияют на их эмоциональное благополучие в начальный период обучения в высшем учебном заведении.

На основе анализа результатов интервью можно выделить следующие тезисы:

1) несформированность у студентов 1-го курса представления о понятии «эмоциональное благополучие» и его структуре Подтверждение высказываниями: «сложно сказать, что это такое», «я не задумывался», «да вроде все нормально, про такое не думал»;

2) недостаточная сформированность ощущения мотивов своих эмоций. Чаще всего свое «плохое настроение» связывают с «большими учебными нагрузками» (боязнь не справиться); «нехватка времени на выполнение заданий» (жесткие дедлайны); «неудобное расписание», «отсутствие времени на обед» и др. 
3) преобладание во взаимодействии неэффективных защитных механизмов и деструктивных эмоциональных реакций. «Хотел делать задание, но в группе был нерабочий настрой, разозлился, что придется делать дома», «сами не делают, просят списать, не могу отказать, но такой подход “бесит”». Также интервьюируемые привели такие примеры, связанные с чувством раздражения, когда преподаватели «спрашивают то, что не задавали, и им не докажешь, что они про это не говорили», т. е. занимают позицию «я всегда прав», «смысл говорить им об этом, все равно ничего не докажешь, лучше молча делать».

Данные выводы позволяют нам предположить, что студенты 1-го курса не вполне готовы к самообеспечению эмоционального благополучия в силу отсутствия знаний об оградительных мерах внешнего и внутреннего деструктивного эмоционального воздействия, а также недостаточности сформированности у них мотивов ощущения своего эмоционального фона.

Все опрошенные респонденты согласились с предложением определить свой уровень эмоционального интеллекта и выразили желание посетить встречи по теме эмоционального благополучия, психологического здоровья, социально-психологической безопасности, если им представится такая возможность.

Далее был разработан цикл внеаудиторных встреч с элементами тренингов в рамках психологического кружка, функционирующего на базе кафедры психологии и общей педагогики Новокузнецкого филиала института Кемеровского государственного университета (НФИ КемГУ). Проведение встреч было запланировано в течение первого семестра 2019-2020 уч. года для студентов-первокурсников. Цель мероприятий - поддержка студентов в непростой период адаптации через развитие эмоционального интеллекта, который согласно исследованиям [20] тесно связан с когнитивными способностями человека, и повышение уровня социально-психологической безопасности при погружении в новый образовательный контекст. Планировалось, что цикл будет включать всего восемь встреч, т. е. один раз в две недели, и будут разделены на два блока. Первый посвящен эмоциональной сфере личности в целом и раскрывает сущность эмоций, механизм их возникновения, проблемы, связанные с алекситимией. Второй блок отражает влияние эмоционального интеллекта на качество жизни в целом и психологическую безопасность в частности, включает техники управления эмоциональными реакциями, особенно в выстраивании коммуникаций, и эмоционального менеджмента в достижении личной и профессиональной эффективности. Формирование осознанности собственных эмоций и эмоциональных реакций позволит студентам улучшить показатели эмпатии, эмоциональной регуляции, качества жизни и благополучия, а также снизит уровень стресса, тревоги [21]. Все это должно положительно сказаться на академической успеваемости.

На первые две недели сентября 2019 г. были запланированы замеры уровня эмоционального интеллекта, контрольные замеры предусмотрены после проведения цикла встреч на конец января 2020 г. Это позволит отследить изменения уровня эмоционального интеллекта. Инструментарием замера уровня EQ до и после реализации внеаудиторных встреч в рамках психологического кружка выбраны тест на эмоциональный интеллект Н. Холла и опросник ЭмИн Д.В. Люсина. Данные методики позволяют измерить общий уровень развития эмоционального интеллекта, а также замерить по отдельным шкалам (составляющим эмоционального интеллекта) и распределить значения согласно нормам теста на низкие, средние и высокие. 


\section{Констатирующий этап}

Эмпирическую базу констатирующего исследования в сентябре 2019-2020 уч. года составили результаты тестирования уровня эмоционального интеллекта студентов 1-го курса НФИ КемГУ, обучающихся по специальностям гуманитарной направленности $(N=73)$.

Первичное тестирование по тесту Н. Холла позволило распределить всех респондентов на три группы. Группу с низким уровнем составили $21,75 \%$ студентов, со средним - 72,3 \% (у 40,7 \% опрошенных отмечаются показатели пограничного значения, близкие к низкому уровню), группу с высоким развитием эмоционального интеллекта сформировали $5,95 \%$ всех студентов.

Анализ результатов структурных компонентов теста Н. Холла показал, что самое низкое среднее значение по нормам теста выявлено в «управление своими эмоциями» (19,71 балла, при этом у юношей 21,47 балла, у девушек - 18,53 балла). Компоненты с самыми высокими - «распознавание и управление чужими эмоциями» (26,79 балла) и «эмоциональная осведомленность» (26,31 балла) - относятся к среднему уровню (табл. 2). В целом по группе не выявлено структурных компонентов с высокими показателями.

Использование корреляционного анализа (коэффициент Пирсона) показало, что параметр «эмоциональной осведомленности» не имеет тесной связи с компонентами «распознавание и управление чужими эмоциями» $(r=0,23)$, «самомотивацией» $(r=0,29)$, что может свидетельствовать об отсутствии достаточных знаний студентов с целью построения стратегии эффективного взаимодействия с окружающим миром и своим профессиональным становлением.

Опросник Д.В. Люсина в целом подтвердил результаты первичного тестирования, полученные по тесту Н. Холла. Высоким и очень высоким уровнем развития эмоционального интеллекта обладают в сумме $11,68 \%$ студентов, средним - 72,26 \% (из них ближе к порогу низкого значения - 48 \%), низкому и очень низкому показателю соответствуют в сумме $16,06 \%$ респондентов (табл. 1).

В анализируемой выборке наиболее низкие значения по нормативным показателям опросника имеют следующие параметры: «управление чужими эмоциями» (17,07 балла), «понимание своих эмоций» (ближе к низкому уровню - 18,66 балла), «управление своими эмоциями» (14,55 балла), «контроль экспрессии» (11,30 балла). По гендерному аспекту более высокие значения в оценках представлены у юношей. Различия показателей в структурных параметрах опросника Д.В. Люсина между юношами и девушками находятся в диапазоне от 1 до 7 баллов.

Такие компоненты из теста, как внутриличностный эмоциональный интеллект, управление эмоциями, понимание эмоций, межличностный эмоциональный интеллект, общий эмоциональный интеллект имеют оценки в диапазоне от 42,64 до 44,03 балла. Они находятся в пределах среднего уровня, но при этом ближе к нижней границе нормативных значений (табл. 3).

Результаты корреляционного анализа показали наличие недостаточно тесных связей структурных параметров теста, таких как «контроль экспрессии», «управление чужими эмоциями», «понимание своих и управление своими эмоциями». Обращает внимание и полученный результат низкой связи $(r=0,22)$ межличностного и внутриличностного эмоционального интеллекта, что, несомненно, может проявиться в неконструктивных моделях поведения и неблагоприятно отразится на установках и целеполагании студентов в будущем. 
Полученные данные позволяют констатировать, что у первокурсниковгуманитариев недостаточно развит эмоциональный интеллект. Это выражается в затруднениях всегда адекватно управлять своими собственными эмоциями и контролировать уровень их интенсивности (особенно в конфликтных ситуациях), нередко они могут зацикливаются на своих отрицательных эмоциях. Сниженная способность распознавания и понимания эмоций других людей накладывает отпечаток на процесс эффективного межличностного общения.

Полученные данные необходимо учитывать в формирующем эксперименте. Кроме того, считаем важным учитывать и гендерные особенности студентов, что позволит повысить эффективность формирующего этапа.

\section{Формирующий этап}

Поскольку социально-психологическая безопасность обеспечивается потенциалом личности, то, на наш взгляд, необходимо сосредоточиться на развитии этого потенциала, т. е. на формировании у студентов стремления к саморазвитию, самореализации, эмоциональной устойчивости и регуляции - всего того, что необходимо для поддержания удовлетворенности от социальных отношений в образовательной среде, ощущения защищенности от неблагоприятных воздействий в межличностных отношениях.

С этой целью мы настоятельно рекомендовали студентам с низким и средним уровнем эмоционального интеллекта посетить цикл внеаудиторных занятий в рамках психологического кружка в первом семестре 2019-2020 уч. года, а студентам с высоким уровнем эмоционального интеллекта предложили посетить данные встречи по их желанию. Таким образом, естественным путем образовались экспериментальная $(N=24)$ и контрольная $(N=49)$ группы, описываемые в настоящем исследовании.

В условиях дефицита общения офлайн у современной молодежи разработанный и реализованный авторский цикл встреч будет способствовать развитию способностей принимать и управлять собственными эмоциями, а также замечать, улавливать и распознавать эмоции других людей. Ведь именно эти способности влияют на развитие внутриличностного и межличностного эмоционального интеллекта и в целом на интегральный показатель и уровень развития общего эмоционального интеллекта. Как было отмечено ранее, развитый эмоциональный интеллект способствует более легкому и комфортному вхождению в новую образовательную среду, академической успешности, эмоциональному благополучию и социально-психологической безопасности студентов цифрового поколения.

\section{Контрольный этап}

После прохождения студентами экспериментальной группы цикла встреч в рамках психологического кружка нами было проведено повторное тестирование с помощью тех же методик Н. Холла и Д.В. Люсина. С их помощью были получены статистически значимые различия.

Суммарная доля в выборке студентов с низким и очень низким уровнем общего эмоционального интеллекта уменьшилась с 16,06 до 13,9 \%, суммарная доля студентов с высоким и очень высоким уровнем значительно увеличилась с 11,68 до 31,5 \%. Это позволяет нам говорить об эффективности используемых форм работы для студентов специальностей гуманитарного профиля. 
таблица 1. Результаты сравнения распределения студентов по группам уровня эмоционального интеллекта по методике В.Д. Люсина, \%

Table 1. Results of comparing the distribution of students among groups of the level of emotional intelligence by the method of V.D. Lucin, in \%

\begin{tabular}{|c|c|c|}
\hline \multirow{2}{*}{$\begin{array}{l}\text { Уровни } \\
\text { Levels, \% }\end{array}$} & \multicolumn{2}{|c|}{$\begin{array}{c}\text { Группы испытуемых (студенты 1-го курса НФИ КемГУ) } \\
\text { Subject groups (1 } 1^{\text {st }} \text { year students of the NFI KemSU) }\end{array}$} \\
\hline & первичное/primary & повторное/repeated \\
\hline $\begin{array}{l}\text { Очень высокий } \\
\text { Very high }\end{array}$ & 3,28 & 8,6 \\
\hline $\begin{array}{l}\text { Высокий } \\
\text { High }\end{array}$ & 8,4 & 22,9 \\
\hline $\begin{array}{l}\text { Средний } \\
\text { Middle }\end{array}$ & 72,26 & 54,6 \\
\hline $\begin{array}{l}\text { Низкий } \\
\text { Low }\end{array}$ & 10,76 & 11,03 \\
\hline $\begin{array}{l}\text { Очень низкий } \\
\text { Very }\end{array}$ & 5,3 & 2,87 \\
\hline
\end{tabular}

Таблица 2. Сравнительные результаты оценки показателей эмоционального интеллекта (тест Н. Холла, в баллах)

Table 2. Comparative results of the assessment of indicators of emotional intelligence (N. Hall test, in points)

\begin{tabular}{|l|c|c|c|c|c|}
\hline $\begin{array}{c}\text { Показатель } \\
\text { Index }\end{array}$ & $\begin{array}{c}\text { Эмоциональная } \\
\text { осведомленность } \\
\text { Emotional awareness }\end{array}$ & $\begin{array}{c}\text { Управление } \\
\text { своими } \\
\text { эмоциями } \\
\text { Management of } \\
\text { your emotions }\end{array}$ & $\begin{array}{c}\text { Самомотивация } \\
\text { Self motivation }\end{array}$ & $\begin{array}{c}\text { Эмпатия } \\
\text { Empathy }\end{array}$ & $\begin{array}{c}\text { Распознавание и понима- } \\
\text { ние эмоций других людей } \\
\text { Recognizing and under- } \\
\text { standing other people's } \\
\text { emotions }\end{array}$ \\
\hline $\begin{array}{l}\text { Первичное } \\
\text { Primary }\end{array}$ & 26,31 & 19,71 & 24,69 & 25,45 & 26,79 \\
\hline $\begin{array}{l}\text { Повторное } \\
\text { Repeated }\end{array}$ & 28,64 & 24,04 & 28,40 & 29,12 & 30,56 \\
\hline
\end{tabular}

таблица 3. Результаты сравнения оценки показателей эмоционального интеллекта (опросник ЭмИн Д.В. Люсина, в баллах)

Table 3. Results of comparing the estimates of indicators of emotional intelligence (questionnaire EmIn D.V. Lyusina, in points)

\begin{tabular}{|l|c|c|c|c|c|c|c|c|c|c|}
\hline $\begin{array}{l}\text { Шкалы эмоционального } \\
\text { интеллекта } \\
\begin{array}{l}\text { Emotional Intelligence } \\
\text { Scales }\end{array}\end{array}$ & $\begin{array}{c}\text { MП } \\
\text { MP }\end{array}$ & $\begin{array}{c}\text { MУ } \\
\text { MU }\end{array}$ & $\begin{array}{c}\text { ВП } \\
\text { VP }\end{array}$ & $\begin{array}{c}\text { ВУ } \\
\text { VU }\end{array}$ & $\begin{array}{c}\text { ВЭ } \\
\text { VE }\end{array}$ & $\begin{array}{c}\text { MЭИ } \\
\text { MPEI }\end{array}$ & $\begin{array}{c}\text { ВЭИ } \\
\text { VEI }\end{array}$ & $\begin{array}{c}\text { ПЭ } \\
\text { PE }\end{array}$ & $\begin{array}{c}\text { УЭ } \\
\text { UE }\end{array}$ & $\begin{array}{c}\text { ОЭИ } \\
\text { ОЕI }\end{array}$ \\
\hline $\begin{array}{l}\text { Первичное } \\
\text { Primary }\end{array}$ & 24,26 & 17,07 & 18,66 & 14,55 & 11,30 & 43,48 & 42,88 & 42,64 & 44,03 & 86,90 \\
\hline $\begin{array}{l}\text { Повторное } \\
\text { Repeated }\end{array}$ & 26,76 & 21,40 & 22,88 & 16,76 & 13,04 & 46,96 & 52,44 & 49,64 & 50,92 & 100,6 \\
\hline
\end{tabular}

Примечания: МП - понимание чужих эмоций; МУ - управление чужими эмоциями; ВП - понимание своих эмоций; ВУ - управление своими эмоциями; ВЭ - контроль экспрессии; МЭИ - межличностный эмоциональный интеллект; ВЭИ - внутриличностный эмоциональный интеллект; ПЭ - понимание эмоций; УЭ - управление эмоциями; ОЭИ - общий эмоциональный интеллект.

Notes: MP - understanding of other people's emotions; MU - management of other people's emotions; VP understanding your emotions; VU - managing your emotions; VE - expression control; MPEI - interpersonal emotional intelligence; VEI - intrapersonal emotional intelligence; PE - understanding emotions; UE - management of emotions; OEI - general emotional intelligence. 
Анализ массива данных контролирующего тестирования по ряду шкал по тесту Н. Холла показал, что после прохождения студентами организованных занятий отмечается статистически достоверный рост по составляющим эмоционального интеллекта. Наибольшая динамика зафиксирована по показателям «эмпатия» и «распознавание и понимание эмоций других людей» на 3,67 и 3,77 \% соответственно.

При оценке уровня парциального эмоционального интеллекта по опроснику ЭмИн Д.В. Люсина отмечаем, что после прохождения занятий у первокурсников специальностей гуманитарного профиля выявлен динамический рост эмоционального интеллекта.

Из таблиц видно, что такие показатели, как «внутриличностный эмоциональный интеллект», «понимание эмоций», «управление эмоциями», получили наибольший прирост на 9,56, 7,00 и 6,89 балла соответственно. Выявленная динамика по данным параметрам позволяет отметить, что у студентов есть стремление к пониманию и осознанию собственных эмоций. Они прилагают усилия для приобретения знаний по их распознаванию, идентификации, пониманию причин возникновения тех или иных эмоций, вербальному выражению. По итогам обсуждения полученных результатов мы можем констатировать, что у студентов достаточно четко сформировано желание овладевать различными техниками управления своими эмоциями. Оно основано на потребности осуществления контроля над внешними нежелательными проявлениями отрицательных эмоций, выстраивании оптимальных стратегий поведения как в системе межличностных взаимодействий, так и в переживании внутриличностного покоя, благополучия.

Выявленные корреляционные зависимости показателей межличностного эмоционального интеллекта по методу корреляции (критерий Пирсона) по данным опросника ЭмИн Д.В. Люсина отражают более тесные связи между шкалами понимания и управления чужими эмоциями (.83 и .78), управление своими эмоциями (.88). Менее тесные связи зафиксированы с показателями шкал понимание своих эмоций (.56). Анализируемые результаты свидетельствуют о потребности студентов в приобретении положительного опыта, освоения оптимальных приемов коммуникации в социальнопсихологическом и профессиональном взаимодействии.

Интегральный показатель общего эмоционального интеллекта по результатам корреляционный анализ данных теста Н. Холла свидетельствует, что имеются тесные связи практически со всеми компонентами. Наиболее сильные связи установлены с параметрами «управление эмоциями» (.89), «самомотивация» (.74) и «распознавание и управление эмоциями других людей» (.77). Иными словами, отмеченные параметры являются определяющими в структуре эмоционального интеллекта и более значимы для респондентов.

Полученные нами положительные динамические изменения после прохождения студентами-первокурсниками авторского цикла встреч подтверждаются аналогичными выводами в работах L.B. Goodmon, A. Arasil, M. Seligman и др. [22-24].

Студенты контрольной группы не участвовали в формирующем процессе, а проходили стандартную программу обучения согласно учебному плану. В январе 2020 г. они также прошли повторное тестирование по опроснику ЭмИн Д.В. Люсина и тесту Н. Холла.

Анализ средних значений по тесту Н. Холла в данной группе показал, что по отдельным параметрам отмечен рост показателей. Например, «эмоциональная осведомлённость» повысилась на 0,81 балла, «управление своими эмоциями» - на 0,97 балла, общий эмоциональный интеллект - на 0,01 балла. Одновременно с этим отмечено сни- 
жение показателей по ряду структурных параметров: «самомотивация» - на 0,79 балла, «эмпатия» - на 0,88 балла, распознавание и управление эмоциями других - на 0,39 балла. Выявленные корреляции по тесту Н. Холла указывают на связь общего эмоционального интеллекта с параметром «самомотивация» $(r=0,85)$ и «эмпатия» $(r=0,90)$, что следует учитывать в дальнейшем в ходе развития эмоционального интеллекта у студентов.

Результаты теста ЭмИн Д.В. Люсина по структурным компонентам «понимание» и «управление чужими эмоциями», аналогично показателям по тесту Н. Холла, также снижаются на 1,30 и 0,70 балла соответственно. Интегрированный показатель общего эмоционального интеллекта в этой группе понизился на 8,10 балла. С общим эмоциональным интеллектом слабые корреляции по параметрам «управление своими эмоциями» $(r=0,25)$, «контроль экспрессии» $(\mathrm{r}=0,27)$, высокие значения корреляционных связей по параметрам «межличностного эмоционального интеллекта» $(r=0,81)$ и «внутриличностного эмоционального интеллекта» $(r=0,88)$.

Отмеченная отрицательная динамика, возможно, связана с повышенной психоэмоциональной и учебной нагрузкой, которой подвергаются все студенты, а первокурсники особенно. Кроме того, это может быть связано с погружением в новую социальную, коммуникативную среду, необходимостью выходить из зоны комфорта, взрослеть, самостоятельно принимать решения и брать за это ответственность. В совокупности это оказывает влияние на снижение общего эмоционального благополучия и ощущения социально-психологической безопасности личности.

\section{Заключение}

Полученные результаты контрольной группы являются сигналом о возможности и даже необходимости включения студентов в специально организованные вузом формы работы по формированию и/или развитию эмоционального интеллекта. Это, несомненно, позитивно скажется на способности осознавать, понимать и объяснять свои внутренние ощущения, чувства, переживания, а также осознавать необходимость в умении распознавать и управлять эмоциями других людей, поддерживать позитивный эмоциональный настрой, сознательно и конструктивно влиять на эмоции и своё поведение и других, а также конструктивно выражать свои чувства и др. В целом такая работа будет способствовать повышению показателей эмоционального благополучия, созданию для каждого студента своей индивидуальной системы социальнопсихологической безопасности. Кроме того, она внесет положительный вклад в развитие человеческого капитала, который позиционируется как существенная компонента устойчивого развития экономики знаний.

\section{СПИСОК ЛИТЕРАТУРЫ}

1. Баева И.А. Психологическая безопасность в образовании. - СПб.: Союз, 2002. - 270 с.

2. Баева И.А., Волкова Е.Н., Лактионова Е.Б. Психологическая безопасность образовательной среды. СПб.: Нестор-История, 2011. - 271 с.

3. Психологическая безопасность образовательной среды региона: теоретические основы и практика создания / И.А. Баева, С.В. Тарасов, Е.Б. Лактионова, Н.Н. Баев, Л.А. Гаязова, Л.И. Шахова. - СПб: ГИЭФПТ, 2019. - 174 с.

4. Сыманюк Э.Э. Психологическая безопасность образовательной среды. - Пермь: Уральский ГУ, 2005.- 162c.

5. Сыманюк Э.Э. Психология профессионально обусловленных кризисов. - М.; Воронеж: Изд-во Моск. психолого-соц. ин-та: МОДЭК, 2004. - 319 с.

6. Hilarski C. How school environments contribute to violent behavior in youth // Journal of Human Behavior in the Social Environment. - 2004. - V. 9. - Iss. 1-2. - P. 165-178. DOI: 10.1300/J137v09n01_11. 
7. Hong J.S., Eamon M.K. Students' perceptions of unsafe schools: an ecological systems analysis // Journal of Child Family Study. - 2012. - V. 21. - Iss. 3. - P. 428-438.

8. Baer M., Frese M. Innovation is not enough: climates for initiative and psychological safety, process innovations, and firm performance // Journal of Organizational Behavior. - 2003. - V. 24. - Iss. 1. - P. 45-68.

9. Баева И.А., Гаязова Л.А. Психологическая безопасность образовательной среды школы и ее психолого-педагогическое сопровождение // Психологическая наука и образование. - 2012. - № 3. C. 30-40. URL: http://psyedu.ru/files/articles/psyedu_ru_2012_3_3015.pdf (дата обращения 12.03.2020).

10. Эксакусто Т.В. Социально-психологическая безопасность субъекта отношений // Вестник СПбГУ. 2010. - Cер. 12. - Вып. 2. - C. 239-344. URL: https://cyberleninka.ru/article/n/sotsialnopsihologicheskaya-bezopasnost-subekta-otnosheniy (дата обращения: 12.03.2020).

11. Зотова О.Ю. Социально-психологическая безопасность личности : дис. ... д-ра психол. наук. - Москва, 2011. -524 с.

12. Лукьянова, Н.А., Родионова, Е.В., Конюхова, Т.В. Социологические основания траектории поддержания психоэмоциональной устойчивости студентов в стрессовых ситуациях // Вестник Томского государственного университета. - 2019. - № 440. - C. 153-159. DOI: 10.17223/15617793/440/21.

13. Сандомирский M.Е. Поколение Z: те, кто будет после // Блог о социальной психологии малых групп, поведенческой экономике, манипуляциях и деструктивном поведении «Социальная психология в действии». URL: http://www.felicidad.ru/2011/07/z.html (дата обращения 12.03.2020).

14. Эриксон Э. Детство и общество. - СПб.: Лет. сад, 2000. - 415 с.

15. Сары-Гузель В.Р. Оптимизация эмоциональной устойчивости личности студента через учебную деятельность: дис. ... канд. психол. наук. - Нижний Новгород, 2002. - 177 с.

16. Воробьева О.А. Психолого-педагогический комфорт как условие воспитания гармонично развитой личности в образовательных учреждениях нового типа: дис. ... канд. пед. наук. - Коломна, 2000. $180 \mathrm{c.}$

17. Куликов Л.В. Детерминанты удовлетворенности жизнью // Общество и политика: Современные исследования, поиск концепций / под ред. В.Ю. Большакова. - СПб.: Изд-во С.-Петерб. ун-та, 2000. C. $476-510$.

18. Тарабакина Л.В. Эмоциональное здоровье школьника: теория и практика психологического сопровождения: дис. ... д-ра психол. наук. - Нижний Новгород, 2000. - 360 с.

19. Холмогорова А.Б, Гаранян Н.Г. Принципы и навыки психогигиены эмоциональной жизни // Психология мотивации и эмоций / под ред. Ю.Б. Гиппенрейтер, М.В. Фаликман. - Москва : ЧеРо: НОУ Моск. психол.-социал. ин-т, 2002. - С. 548-557.

20. Cittoor Girija Navaneedhan, Kamalanabhan T.J. Is emotional intelligence an essential element in global learning environment to become socially responsible innovators? // Technium Social Sciences Journal. 2020. - V. 5. - P. 12-25. URL: https://techniumscience.com/index.php/socialsciences/article/view/171/88 (дата обращения: 12.03.2020).

21. Mindfulness in allied health and social care professional education: a scoping review / E.A. Kinsella, K. Smith, S. Bhanji, R. Shepley, A. Modor, A. Bertrim // Disability and Rehabilitation. - 2020. - V. 42. Iss. 2. - P. 283-295. DOI: 10.1080/09638288.2018.1496150.

22. Positive psychology course and its relationship to well-being, depression, and stress / L.B. Goodmon, A.M. Middleditch, B. Childs, S.E. Pietrasiuk // Teaching of Psychology. - 2016. - V. 43. - Iss. 3. - P. $232-237$. DOI: $10.1177 / 0098628316649482$.

23. Positive psychology course: a way to improve well-being / A. Arasil, F. Turan, B. Metin, H.S. Ertas, N. Tarhan // Journal of Education and Future - Egitim Ve Gelecek Dergisi. - 2020. - Iss. 17. - P. 15-23. DOI:10.30786/jef.591777.

24. Positive psychology progress - empirical validation of interventions / M. Seligman, T.A. Steen, N. Park, C. Peterson // American Psychologist. - 2005. - V. 60. - Iss. 5. - P. 410-421. DOI: 10.1037/0003066X.60.5.410.

Поступила 18.04.2020 г. 
UDC 378.015.31:159.942

\title{
EMOTIONAL WELL-BEING AS AN INDICATOR OF SOCIO-PSYCHOLOGICAL SAFETY OF STUDENTS
}

\author{
Elena V. Rodionova 1 , \\ eva@tpu.ru \\ Tatiana V. Konyukhova ${ }^{1}$, \\ konykhova@tpu.ru \\ Ekaterina T. Konyukhova2, \\ konjuhova50@mail.ru
}

\author{
${ }^{1}$ National Research Tomsk Polytechnic University, \\ 30, Lenin Avenue, Tomsk, 634050, Russia \\ 2 Kemerovo State University in Novokyznetsk, \\ 23, Tsiolkovsky street, Novokuznetsk, 654041, Russia
}

Elena V. Rodionova, Cand. Sc., associate professor, National Research Tomsk Polytechnic University.

Tatiana V. Konyukhova, Cand. Sc., associate professor, National Research Tomsk Polytechnic University.

Ekaterina T. Konyukhova, Cand. Sc., associate professor, Kemerovo State University in Novokyznetsk.

The research deals with the issue of social and psychological safety and emotional well-being of students. Psychological safety is manifested in the subject sense of security, the reference importance of the environment for him and his satisfaction with the processes of interaction. An important role here is the state of emotional background, awareness of emotions by the subject, ability to express and regulate them. One of the conditions for gaining emotional well-being is the developed emotional intelligence. Today it is considered as a necessary element that allows you to control yourself in various situations, build relationships, socialize in life. This makes it possible to find a state of confidence, calmness and satisfaction. The aim of the research is to evaluate the effectiveness of classes on the development of emotional intelligence of $1^{\text {st }}$ year students, affecting the formation and/or maintenance of emotional well-being and sociopsychological safety. Methods. Methodological basis was performed by general theoretic methods of scientific analysis, synthesis. Qualitative in-depth interviews were used as practical methods; diagnostic method (Emotional Intelligence (EmIn) questionnaire by D.V. Lusin, test of Emotional Intelligence by N. Hall); experimental method for summative and formative assessment, controlling stages of the study; methods of mathematical statistics. Results. Formative activity allows the development of emotional intelligence affecting the maintenance of a sufficient level of overall emotional well-being of $1^{\text {st }}$ year students and the sense of social and psychological security of the individual.

Key words: Social and psychological safety, students' emotional well-being, emotional intelligence, digital generation, emotional awareness, empathy, students' mental health.

\section{REFERENCES}

1. Baeva I.A. Psikhologicheskaya bezopasnost v obrazovanii [Psychological security in education: monograph]. St. Petersburg, Soyuz Publ., 2002. 270 p.

2. Baeva I.A., Volkova E.N., Laktionova E.B. Psikhologicheskaya bezopasnost obrazovatelnoy sredy [Psychological safety of the educational environment]. St. Petersburg, Nestor-Istoriya Publ., 2011. 271 p. 
3. Baeva I.A., Tarasov S.V., Laktionova E.B., Bayev N.N., Gayazova L.A., Shakhova L.I. Psikhologicheskaya bezopasnost obrazovatelnoy sredy regiona: teoreticheskie osnovy i praktika sozdaniya [Psychological security of the educational environment of the region: theoretical foundations and practice of creation]. St. Petersburg, GIEFPT Publ., 2019. 174 p.

4. Symanyuk E.E. Psikhologicheskaya bezopasnost obrazovatelnoy sredy [Psychological security in education space]. Perm, Uralskiy GU Publ., 2005. 162 p.

5. Symanyuk E.E. Psikhologiya professionalno obuslovlennykh krizisov [Psychology of professionally determined crises]. Moscow, Moscow Psychology Social Institute Publ.; Voronezh, MODEK Publ., 2004. 319 p.

6. Hilarski C. How school environments contribute to violent behavior in youth. Journal of Human Behavior in the Social Environment, 2004, vol. 9, Iss. 1-2, pp. 165-178. DOI: 10.1300/J137v09n01_11.

7. Hong J.S., Eamon M.K. Students' perceptions of unsafe schools: an ecological systems analysis. Journal of Child Family Study, 2012, vol. 21, Iss. 3, pp. 428-438.

8. Baer M., Frese M. Innovation is not enough: climates for initiative and psychological safety, process innovations, and firm performance. Journal of Organizational Behavior, 2003, vol. 24, Iss. 1, pp. 45-68.

9. Baeva I.A., Gayazova L.A. Psikhologicheskaya bezopasnost obrazovatelnoy sredy shkoly i ee psikhologopedagogicheskoe soprovozhdenie [Psychological safety of the educational environment of the school and its psychological and pedagogical support]. Psikhologicheskaya nauka i obrazovanie, 2012, no. 3, pp. 30-40. Available at: http://psyedu.ru/files/articles/psyedu_ru_2012_3_3015.pdf (accessed 12 March 2020).

10. Eksakusto T.V. Sotsialno-psikhologicheskaya bezopasnost subekta otnosheniy [Psychological safety of the school's educational environment and its psychological and pedagogical support]. Vestnik SPbGU, 2010, Series 12, Iss. 2, pp. 239-344. Available at: https://cyberleninka.ru/article/n/sotsialno-psihologicheskayabezopasnost-subekta-otnosheniy (accessed 12 March 2020).

11. Zotova O.Yu. Sotsialno-psikhologicheskaya bezopasnost lichnosti. Dis. Dokt. nauk [Socio-psychological security of the individual. Dr. Diss.]. Moscow, 2011. 524 p.

12. Lukyanova N.A., Rodionova E.V., Konyuhova T.V. Sotsiologicheskie osnovaniya traektorii podderzhaniya psikhoemotsionalnoy ustoychivosti studentov $\mathrm{v}$ stressovykh situatsiyakh [Sociological reasons of the supporting trajectory of the students' psycho-emotional stability in stressful situations]. Vestnik Tomskogo gosudarstvennogo universiteta, 2019, no. 440, pp. 153-159. DOI: 10.17223/15617793/440/21.

13. Sandomirskiy M.E. Pokolenie Z: te, kto budet posle [Generation Z: those who will be after]. Blog $o$ sotsialnoy psikhologii malykh grupp, povedencheskoy ekonomike, manipulyatsiyakh $i$ destruktivnom povedenii «Sotsialnaya psikhologiya $v$ deystvii» [Blog about social psychology of small groups, behavioral economics, manipulation and destructive behavior. Social Psychology in Action]. Available at: http://www.felicidad.ru/2011/07/z.html (accessed 12 March 2020).

14. Erikson E. Detstvo i obshchestvo [Childhood and society]. St. Petersburg, Let. sad Publ., 2000. 415 p.

15. Sary-Guzel V.R. Optimizatsiya emotsionalnoy ustoychivosti lichnosti studenta cherez uchebnuyu deyatelnost. Dis. Kand. nauk [Optimization of emotional stability of a student's personality through educational activity. Cand. Diss.]. Nizhniy Novgorod, 2002. 177 p.

16. Vorobeva O.A. Psikhologo-pedagogicheskiy komfort kak uslovie vospitaniya garmonichno razvitoy lichnosti v obrazovatelnykh uchrezhdeniyah novogo tipa. Dis. Kand. nauk [Psychological and pedagogical comfort as a condition for upbringing a harmoniously developed personality in educational institutions of a new type. Cand. Diss.]. Kolomna, 2000. 180 p.

17. Kulikov L.V. Determinanty udovletvorennosti zhiznyu [Determinants of life satisfaction]. Obshchestvo $i$ politika: sovremennye issledovaniya, poisk kontsepciy [Society and politics: modern research, the search for concepts]. Ed. by V.Yu. Bolshakov. St. Petersburg, St. Petersburg University Publ., 2000. pp. 476-510.

18. Tarabakina L.V. Emotsionalnoe zdorove shkolnika: teoriya i praktika psikhologicheskogo soprovozhdeniya. Dis. Dokt. nauk [Emotional health of a student: theory and practice of psychological support. Dr. Diss.]. Nizhniy Novgorod, 2000. 360 p.

19. Kholmogorova A.B., Garanyan N.G. Printsipy i navyki psikhogigieny emotsionalnoy zhizni [The principles and skills of mental health emotional life]. Psihologiya motivatsii i emotsii [Psychology of motivation and emotions]. Eds. Yu.B. Gippenreyter, M.V. Falikman. Moscow, CheRo Publ., NOU Moscow Psychology Social Institute Publ., 2002. pp. 548-557.

20. Cittoor Girija Navaneedhan, Kamalanabhan T.J. Is emotional intelligence an essential element in global learning environment to become socially responsible innovators? Technium Social Sciences Journal, 2020, vol. 5, pp. 12-25. Available at: https://techniumscience.com/index.php/socialsciences/article/view/171/88 (accessed 12 March 2020).

21. Kinsella E.A., Smith K., Bhanji S., Shepley R., Modor A., Bertrim A. Mindfulness in allied health and social care professional education: a scoping review. Disability and Rehabilitation, 2020, vol. 42, Iss. 2, pp. 283-295. DOI: 10.1080/09638288.2018.1496150. 
22. Goodmon L.B., Middleditch A.M., Childs B., Pietrasiuk S.E. Positive psychology course and its relationship to well-being, depression, and stress. Teaching of Psychology, 2016, vol. 43, Iss. 3, pp. 232-237. DOI: 10.1177/0098628316649482.

23. Arasil A., Turan F., Metin B., Ertas H.S., Tarhan N. Positive psychology course: a way to improve wellbeing. Journal of Education and Future - Egitim Ve Gelecek Dergisi, 2020, Iss. 17, pp. 15-23. DOI:10.30786/jef.591777.

24. Seligman M., Steen T.A., Park N., Peterson C. Positive psychology progress - Empirical validation of interventions. American Psychologist, 2005, vol. 60, Iss. 5, pp. 410-421. DOI: 10.1037/0003-066X.60.5.410.

Received: 18 April 2020. 